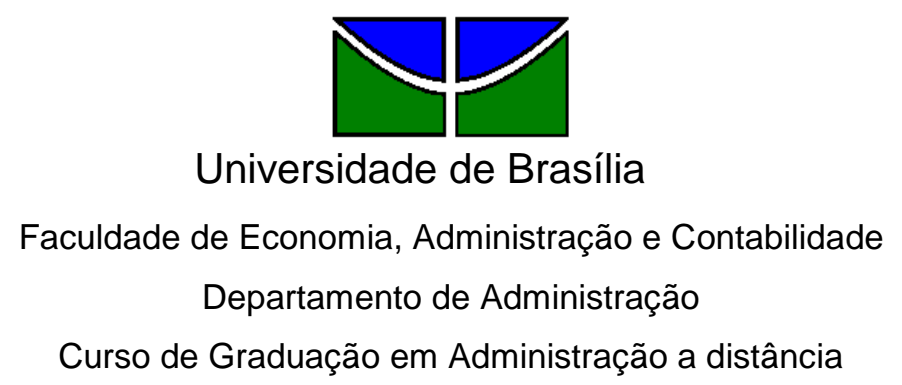

CLAUDIA RODRIGUES MARTINS

\title{
A CONTRIBUIÇÃO DE UM SISTEMA DE INFORMAÇÃO NO PROCESSO DECISÓRIO
}

Brasília - DF 


\section{CLAUDIA RODRIGUES MARTINS}

\section{A CONTRIBUIÇÃO DE UM SISTEMA DE INFORMAÇÃO NO PROCESSO DECISÓRIO}

Monografia apresentada a Universidade de Brasília (UnB) como requisito parcial para obtenção do grau de Bacharel em Administração.

Professor Orientador: Especialista em Docência e Metodologia do Ensino Superior, Wilian Gomes Xavier 
Martins, Claudia Rodrigues.

A Contribuição de um Sistema de Informação no Processo Decisório / Claudia Rodrigues Martins. - Brasília, 2010.

22 f. : il.

Monografia (bacharelado) - Universidade de Brasília, Departamento de Administração - EaD, 2010.

Orientador: Prof. Wilian Gomes Xavier, Departamento de Administração.

1. Sistema de Informação. 2. Processo Decisório. 3. Informações Gerenciais. 


\section{CLAUDIA RODRIGUES MARTINS}

\section{A CONTRIBUIÇÃO DE UM SISTEMA DE INFORMAÇÃO NO PROCESSO DECISÓRIO}

A Comissão Examinadora, abaixo identificada, aprova o Trabalho de Conclusão do Curso de Administração da Universidade de Brasília do (a) aluno (a)

\section{Claudia Rodrigues Martins}

\section{Especialista em Docência e Metodologia do \\ Ensino Superior, Wilian Gomes Xavier \\ Professor-Orientador}

\footnotetext{
Msc, José Carneiro da Cunha Oliveira Neto,

Professor-Examinador-Supervisor
}

\author{
Especialista, Wolney Resende de \\ Oliveira \\ Professor-Examinador
}


Dedico este trabalho à minha mãe, Maria Alice, que me sustentou com suas orações e dedicou apoio absoluto durante todo este percurso, tornando minha jornada mais fácil. 
AGRADECIMENTOS

Agradeço a Deus por permanecer comigo durante mais este percurso, por me dar forças quando eu achava que não conseguiria, e por colocar pessoas tão especiais ao meu lado, me incentivando e apoiando nos momentos difíceis. Agradeço à minha família pelo apoio, especialmente minha mãe, por todas as orações, incentivos, motivações e por mais uma vez acreditar em mim. 
Grande é o Senhor e mui digno de louvor. SI 48:1 


\section{RESUMO}

Visando obter uma administração mais assertiva que possa minimizar riscos, diante de situações em que a Empresa venha a se encontrar em situação de exposição, mediante crises econômicas mundiais ou até mesmo problemas provocados por catástrofes naturais, faz-se necessário que o gestor tenha em mãos ferramentas que possam auxiliá-lo na tomada de decisões. Por este motivo, há a necessidade de obter informações que o auxiliem na correta administração. Diante do exposto, este trabalho tem por objetivo destacar como um sistema de informações pode contribuir para a tomada de decisões, destacando alguns relatórios contábeis que evidenciam a realidade financeira e econômica de uma Empresa, e por meio destes relatórios gerenciais, bem como demonstrações contábeis, é possível identificar índices representativos, que auxiliam na adoção de estratégias para a tomada de decisões. Serão abordados alguns destes índices, com a descrição de suas utilidades no campo gerencial. Também será abordada a metodologia utilizada para a coleta destes dados gerenciais, onde através das demonstrações contábeis são absolutamente possíveis de serem visualizados.

Palavras-chave: Relatórios Gerenciais. Demonstrações Contábeis. 


\section{SUMÁRIO}

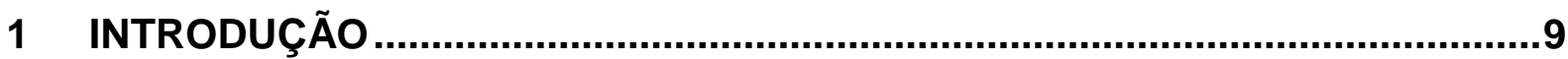

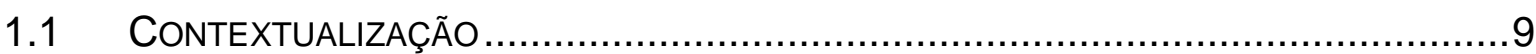

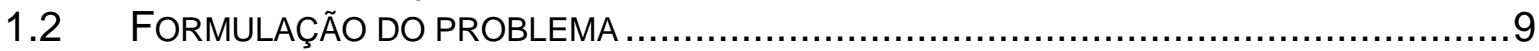

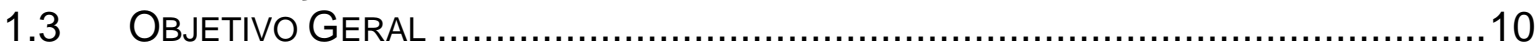

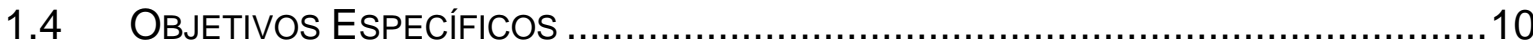

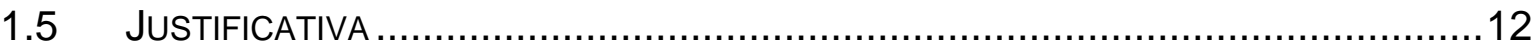

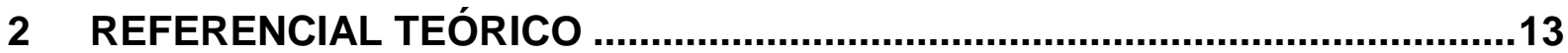

2.1 SURGIMENTO E EVOLUÇÃO DA INFORMAÇÃO GERENCIAL ...............................13

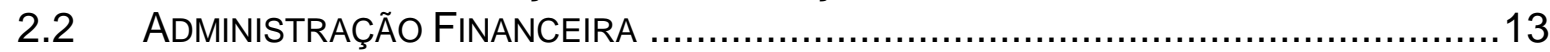

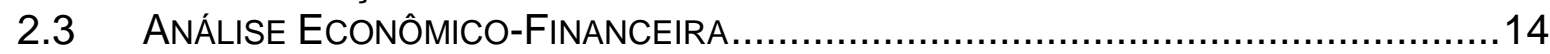

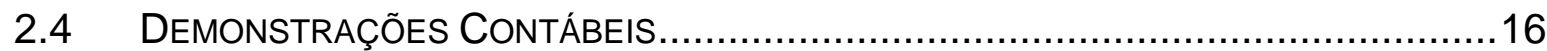

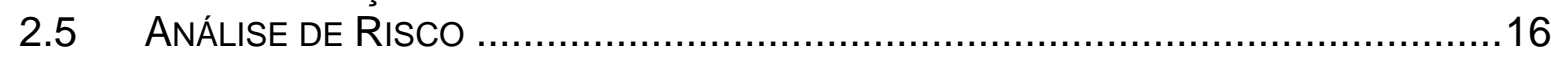

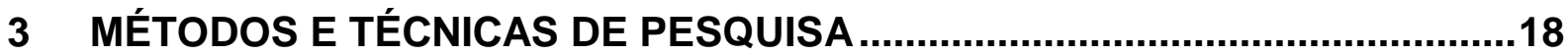

3.1 CARACTERIZAÇÃO DA ORGANIZAÇÃO, SETOR OU ÁREA …...............................18

3.2 POPULAÇÃO E AMOSTRA OU PARTICIPANTES DO ESTUDO.............................19

3.3 CARACTERIZAÇÃO DOS INSTRUMENTOS DE PESQUISA ..................................19

3.4 PROCEDIMENTOS DE COLETA E DE ANÁLISE DE DADOS ................................19

4 RESULTADOS E DISCUSSÃO

5 CONCLUSÕES E RECOMENDAÇÕES .....................................................21

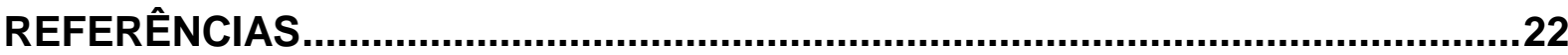




\section{INTRODUÇÃO}

Nos últimos anos tem havido inúmeras publicações mencionando a crise econômica mundial. Vários informativos noticiam diariamente sobre questões que desencadeiam problemas de natureza econômica em muitos Países, ocasionando prejuízos, promovendo preocupações a grandes líderes mundiais, levando-os a tomarem decisões que desagradam a muitos, promovendo uma cadeia de reações, e com isso levando empresários de diversos níveis a se preocuparem com relação a estratégias que possibilitem uma correta gestão, buscando evitar a exposição de suas empresas, com o objetivo de mantê-las sob uma estrutura, minimizando os riscos, objetivando o lucro, traçando estratégias em busca do retorno desejado.

Face ao exposto, o presente trabalho tem por objetivo evidenciar como um sistema de informações pode contribuir para a tomada de decisões, e quais são os mecanismos mais usuais que demonstram se a empresa está ou não inserida em situação de risco, sendo possível a adoção de medidas para dar continuidade às suas atividades.

\subsection{Contextualização}

Diante da necessidade de se fazer uma correta e assertiva administração, serão demonstradas algumas das ferramentas que auxiliam o gestor na tomada de decisões, tendo em vista estar suprido de informações extraídas dos relatórios gerenciais da Empresa, onde terá a exata noção da real situação.

\subsection{Formulação do problema}

Está cada vez maior o grau de risco enfrentado pelas empresas, no que concerne às oscilações do mercado globalizado, bem como problemas causados pela própria natureza, em que é possível perceber que, havendo determinados 
problemas em alguns Países, isto certamente irá provocar uma cadeia de reações, podendo ocasionar prejuízos financeiros de tamanhos inestimáveis.

Devido a essa exposição financeira e estrutural, há a necessidade de que os gestores estejam munidos de ferramentas que os possibilitem tomarem decisões em tempo hábil, objetivando permanecer no mercado globalizado, porém de forma segura, no sentido de terem condições de dar seqüência às atividades pertinentes à Empresa, e isso é possível pela utilização de um apropriado sistema de informações gerenciais.

Apesar de haver esse consenso, pode-se afirmar que um Sistema de Informações Gerenciais mostra-se como sendo recurso devidamente qualificado e abrangente para suprir os gestores de informações, de tal modo que lhes possibilitem tomarem decisões e estabelecerem estratégias de continuidade dos negócios?

\subsection{Objetivo Geral}

Evidenciar o grau de importância das informações gerenciais, enfatizando os métodos correspondentes para alcançar esse nível de assessoramento, de tal forma que se coloquem disponíveis para suprir os gestores com informações relacionadas aos negócios das empresas, contribuindo com o processo de tomada de decisões, com vistas a minimizar a exposição aos riscos existentes no mercado.

\subsection{Objetivos Específicos}

a) Apresentar histórico relacionado ao surgimento das informações gerenciais, principalmente como extensão das Demonstrações Contábeis.

b) Indicar os métodos usualmente reconhecidos pelo mercado como sendo de melhores práticas corporativas, no que diz respeito à obtenção de informações gerenciais. 
c) Relacionar a importância e participação do procedimento reconhecido como Mapeamento de Processos Operacionais na determinação ou identificação de pontos prioritários sob o enfoque gerencial.

Em se tratando de informações gerenciais, cabe ressaltar o surgimento do processo contábil, que sob a ótica gerencial, supre os gestores com informações específicas para a tomada de decisões.

É oportuno destacar que, desde a antiguidade, o processo contábil assume diretrizes com características cada vez mais evidentes no âmbito administrativo, pois, não apenas serviam para registrar e avaliar as riquezas existentes, mas com o passar do tempo, vem assumindo uma posição de apoio, sendo vista como fator decisivo ao relatar quantitativamente o desempenho da Empresa, seja em termos já realizados, como em termos de projeções futuras, evidenciados em suas Demonstrações Contábeis.

O objetivo central das informações gerenciais, diz respeito a dar suporte à administração para a correta tomada de decisões. Face ao exposto, têm sido adotadas como práticas corporativas na obtenção das referidas informações, relatórios que demonstrem a estrutura econômica e financeira da empresa tais como, Demonstrações Contábeis, Balancetes, Notas Explicativas, e outros que, expostos de forma eficaz, virão a contribuir para o sucesso das decisões no âmbito administrativo.

Todavia, considerando que a administração da empresa está subsidiada em termos de informações, podendo atuar de forma correta na tomada de decisões, é imprescindível destacar que, para o alcance do sucesso das diretrizes da empresa, será necessário um eficiente processo operacional.

Os relatórios obtidos por meio da contabilidade refletem a realidade da empresa de forma resumida, portanto, uma vez sendo considerados de vital importância para uma empresa, sendo exigidos por lei, servirão como direcionadores para a tomada de decisões.

Conseqüentemente, as decisões administrativas são baseadas em fatos fidedignos, reais e decisivos, possibilitando assim ações estratégicas que conduzirão a empresa à obtenção do tão almejado sucesso. 


\subsection{Justificativa}

Com base nos últimos acontecimentos a nível global, no que se refere à problemática econômica e financeira que ocasiona perdas aos investidores em todo o mundo, e também proporciona prejuízos empresariais, e em se tratando de Administração, decisões intempestivas podem causar danos que podem levar ao fechamento da empresa,

Uma organização pode enfrentar diferentes problemas de cunho empresarial, ou seja, pode ser afetada pela dificuldade de exportação ou importação, pela desvalorização cambial, até mesmo por fatores da natureza, entretanto, é necessário estar preparada para tomar decisões que possam manter a empresa nos trilhos, independente do tipo de fator externo ou interno que esteja ocorrendo.

Por isso, a presente pesquisa objetiva demonstrar métodos que podem ser utilizadas pelos gestores, com o propósito de que conheçam a operacionalização da empresa, e, de posse dessas informações, estejam seguros para tomar as decisões que se fizerem necessárias. 


\section{REFERENCIAL TEÓRICO}

Objetivando dar ênfase às ferramentas e mecanismos existentes que auxiliam o gestor na sua administração, serão descritos neste tópico algumas considerações a respeito da evolução da informação gerencial, administração financeira, a existência da análise econômico financeira, bem como das demonstrações contábeis e por fim, serão considerados alguns fatores de análise de risco, que podem minimizar ou até mesmo evitar uma grande exposição da Empresa, nos momentos de crise mundial ou problemas semelhantes que promovam preocupações no mercado.

\subsection{Surgimento e evolução da informação gerencial}

Diariamente a população se vê envolvida em situações que as remete às oscilações financeiras mundiais, taxas de juros, mercado de ações, crises etc. Situações que para os Empresários podem representar grandes perdas, se não forem cuidadosamente acompanhadas e analisadas, com o objetivo de que não venham a sofrer grandes impactos e que possam se recuperar ou se proteger frente às incertezas originadas. De acordo com BODIE \& MERTON:

As decisões financeiras envolvem custos e benefícios que se estendem ao longo do tempo. Os tomadores de decisões financeiras nas famílias, nas empresas e nas agências do governo precisam avaliar se gastar dinheiro hoje se justifica pelos benefícios esperados no futuro. (BODIE \& MERTON, 1999, p.99)

\subsection{Administração Financeira}

Para Gitman (2006), para uma correta e assertiva administração financeira, faz-se necessário conhecer os fatores que envolvem a atividade financeira, como mensurar cada uma delas e como prever a existência ou não de situações que venham a causar prejuízos à Empresa. 
O Objetivo do Administrador Financeiro é fundamentalmente maximizar o lucro e, para que isso seja possível, é necessário administrar os riscos, o que remete à necessidade de se conhecer o Balanço Empresarial para então tomar decisões, através de investimentos e financiamentos. Esse é o principal motivo para que se tenha conhecimento da composição dos itens dos ativos, passivos e recursos disponíveis.

\begin{tabular}{|c|c|c|c|}
\hline \multicolumn{4}{|c|}{ Análise e Planejamento Financeiros } \\
\hline & Balanço & & \\
\hline \multirow{4}{*}{$\begin{array}{l}\text { Decisões de } \\
\text { Investimento }\end{array}$} & Ativo & Passivo & \multirow{4}{*}{$\begin{array}{l}\text { Decisões de } \\
\text { Financiamento }\end{array}$} \\
\hline & Circulante & Circulante & \\
\hline & Ativo & Recursos Realizáveis & \\
\hline & Permanente & Longo prazo & \\
\hline
\end{tabular}

Fonte: Assaf Neto - Estrutura e Análise de Balanços

\subsection{Análise Econômico-Financeira}

Para Assaf Neto (1981), é necessário um conhecimento aprofundado do mercado de atuação, para que se possa compreender melhor a atividade empresarial. Esse autor aborda as análises horizontais e verticais, destacando também a importância de que haja uma análise econômico-financeira mais aprimorada, que acompanhe o mercado, viabilizando um melhor desempenho para a empresa. De acordo com Assaf Neto:

\footnotetext{
A análise de balanços visa relatar, com base nas informações contábeis fornecidas pelas empresas, a posição econômico-financeira atual, as causas que determinam a evolução apresentada e as tendências futuras. Em outras palavras, pela análise de balanços extraem-se informações sobre a posição passada, presente e futura (projetada) de uma empresa. (ASSAF NETO, 2002, p.48)
}

A Análise Horizontal analisa os valores de um mesmo grupo de contas, em diferentes exercícios sociais. Portanto, verifica o número índice igual à relação 
existente entre o valor de um grupo contábil em determinada data $(\mathrm{Vd})$ e o valor obtido na data base $(\mathrm{Vb})$. A fórmula a seguir detalhada indica essa metodologia.

Número-Índice $=(\mathrm{Vd} / \mathrm{Vb}) \times 100$

Por essa exposição, a análise demonstrará a evolução existente entre exercícios diferentes.

A Análise Vertical também faz uma análise, porém em percentual, objetivando apurar cada item por grupo demonstrado contabilmente.

Com relação ao Passivo, este pode provocar instabilidade financeira, pois poderá exprimir incapacidade e saldar compromissos, o que põe a empresa em estado de fragilidade.

Naturalmente, para honrar compromissos, a tendência é buscar recursos, o que promove taxas de juros elevadas, provocando assim o endividamento da Instituição.

Endividamento $=$ Passivo Total $/$

Patrimônio Líquido

Para avaliar a viabilidade econômica de uma empresa, existem as ferramentas de Retorno sobre o Investimento - ROI, conforme demonstrado a seguir:

\begin{tabular}{|l|l|l|l|}
\hline Lucro Operacional & Investimento & Passivo Oneroso & $\begin{array}{l}\text { Despesas } \\
\text { Financeiras }\end{array}$ \\
\cline { 3 - 4 } & & Patrimônio Líquido & Lucro Líquido \\
\hline
\end{tabular}

O Passivo Oneroso representa os financiamentos bancários do passivo circulante e exigível a longo prazo.

O ROI - Retorno sobre o Investimento é calculado da seguinte forma: 


$$
\begin{aligned}
& \mathrm{ROI}=\text { Lucro Operacional } / \\
& \text { Investimento }
\end{aligned}
$$

O Cálculo do ROI serve para demonstrar o retorno sobre o investimento, e deve ser comparado com o retorno do Patrimônio Líquido e com o custo do endividamento.

\subsection{Demonstrações Contábeis}

ludícibus (1994) relata que as Demonstrações Contábeis têm por finalidade apresentar a posição financeira e patrimonial da empresa em determinada data, evidenciam a situação financeira da empresa, e devem servir como ferramentas fidedignas para a correta tomada de decisões.

"A Contabilidade é, objetivamente, um sistema de informação e avaliação destinado a prover seus usuários com demonstrações e análises de natureza econômica, financeira, física e de produtividade, com relação à entidade objeto de contabilização". (MANUAL DE CONTABILIDADE (ludícibus et. al. 1994, p.58)

\subsection{Análise de Risco}

No que concerne à análise de risco, é imprescindível conhecer os riscos de mercado nos quais a empresa estará submetida, considerando que os projetos para o desenvolvimento da instituição, bem como as estratégias a serem desenvolvidas, necessitam reconhecer o fator risco, a fim de que seja possível uma gestão correta e assertiva.

Assaf Neto (1981) afirma que a Administração do Capital de Giro na economia Brasileira necessita de demonstrações técnicas de gestão, risco, tomada de decisões, fluxos de caixa, análise e dimensionamento dos investimentos em 
capital de giro, bem como parâmetros para uma correta administração de riscos. Conforme CAPELLETO.

"A mensuração de riscos no sistema financeiro é marcada com a publicação
do Acordo de Capital da Basiléia (BCBS, 1988), pelo BCBS (Comitê de
Basiléia sobre Supervisão Bancária), que estabeleceu a aferição do valor
em risco pela relação entre os ativos e o patrimônio líquido, modificando o
conceito vigente que considerava o endividamento calculado pela razão
entre o passivo e o patrimônio líquido. A mudança conduziu os estudos para
os riscos inerentes às atividades cotidianas das instituições financeiras,
destacando-se aqueles relacionados aos riscos de crédito, taxa de juros,
câmbio, liquidez e, mais recentemente, ao risco operacional".
(CAPELLETTO et. al, 2008)

SANVICENTE (1990) entende que existem diversas situações enfrentadas no dia a dia que tendem a mensurar custos e resultados, diferentes tipos de se calcular a taxa de retorno para um investimento e as dificuldades enfrentadas no dia a dia pelo contador ou pelo "controller" com relação à melhor opção, ou seja, tomada de decisão.

Estas diferentes formas de mensurar resultados, considerando diferentes tipos de administrar investimentos, estão diretamente relacionadas ao retorno a ser alcançado, visto que, por meio das informações obtidas pelo contador é que serão tomadas as decisões, portanto será um mecanismo em destaque para a correta administração.

FREZATTI et. al. (2007) cita a importância da contabilidade financeira e da contabilidade gerencial na tomada de decisões, concluindo que ambas são de grande importância, pois trazem em seus relatórios informações com o grau de confiabilidade necessário.

GUERREIRO (1992) entende que através das informações contábeis, gestores, resultados analíticos da empresa, gestores econômicos da empresa e sistema de informação, é possível traçar um modelo de sistema de informação contábil que irá contribuir para o bom desenvolvimento da empresa. Conforme entendimento de SANTOS, Edilene Santana.

\footnotetext{
"Toda organização é constituída e se desenvolve a partir de decisões que, no seu conjunto, singularizam a sua identidade e determinam cada uma de suas opções". (SANTOS, Edilene Santana et. al, 1998)
} 


\section{MÉTOdOS E TÉCNICAS DE PESQUISA}

O método de pesquisa a ser desenvolvido no presente trabalho terá como base os balancetes patrimoniais das instituições financeiras, onde serão comparados relatórios de meses diferentes, a fim de visualizar o desenvolvimento financeiro da instituição, no que concerne a análise de risco e liquidez, bem como o relatório de risco operacional, objetivando análise de risco de mercado, uma vez que uma empresa necessita gerar lucros, e para que isso seja possível, faz-se necessário uma administração precisa, assertiva, com êxito.

Por este motivo serão evidenciadas junto aos métodos e técnicas de pesquisa Análise Horizontal e Vertical, Índices de Liquidez e Análise de Risco, facilitando o processo de informações que poderão ser adquiridos na análise dos balancetes pesquisados.

\subsection{Caracterização da organização, setor ou área}

Para se alcançar os resultados esperados, será preciso analisar os riscos nos quais a Empresa está submetida. No entanto, a ausência de dados que venham a demonstrar os riscos operacionais e de mercado, poderão comprometer a eficiência da gestão, podendo promover falhas administrativas. Desse modo, com base em relatórios publicados na internet, embora limitados, porém considerados como Análise documental, há a possibilidade de identificar processos adequados que minimizem riscos, e possibilitem um melhor controle, facilitando o atingimento de metas.

Com relação à caracterização da organização, setor ou área do objeto de estudo, serão observados para o desenvolvimento da pesquisa a coleta de dados, análise de resultados e demonstração de índices. O tipo de pesquisa será descritivo e quantitativo, pois serão analisados relatórios referentes à empresa, e também dados numéricos obtidos nos balancetes. 


\subsection{População e amostra ou participantes do estudo}

O modelo de amostra a ser trabalhado será diretamente relacionado a resultados obtidos com base em relatório quantitativo, com vistas a identificar o desenvolvimento da instituição em um determinado período. Com relação a riscos, em instituições financeiras, sabe-se que estão diretamente expostos à oscilação econômica, ou seja, à movimentação econômica do País, no que concerne às taxas de juros, que fazem com que o mercado reaja positiva ou negativamente às decisões referentes à economia, e com isto fazem com que os gestores adotem posturas diferenciadas na tomada de decisões.

Tendo como base de estudo instituições financeiras, e por serem analisados relatórios, como balancetes, não será utilizada "população e amostra" para o presente estudo, e sim "participante do estudo", no caso, relatórios de instituições financeiras.

\subsection{Caracterização dos instrumentos de pesquisa}

O projeto terá como base principal publicações na internet, entretanto serão adotados como bases secundárias Livros e artigos científicos.

\subsection{Procedimentos de coleta e de análise de dados}

Para a coleta de dados e análise, será observado o relatório "balancete" disponibilizado na internet, segundo os critérios de publicação adotados no Brasil, com o objetivo de explorar o conteúdo disponibilizado no relatório, buscando critérios interpretativos que possibilitem a correta identificação quanto à situação da empresa face à exposição a riscos de mercado. 


\section{RESULTADOS E DISCUSSÃO}

Com o intuito de elaborar uma análise financeira, com base em relatórios gerenciais, objetivando uma avaliação da real situação financeira e administrativa em que a Empresa se encontra, são utilizados métodos para a realização de cálculos de índices, que demonstram se a empresa tem condições de saldar seus compromissos financeiros, se tem recuperado os investimentos feitos, e se tem alcançado os objetivos traçados.

A análise de demonstrações financeiras possibilita uma visualização eficaz, quanto aos rendimentos alcançados, capacitando o gestor a tomar decisões em razão da realidade financeira exposta nos relatórios.

Portanto, dispondo o gestor de ferramentas que o auxiliem de forma correta, será possível acompanhar o andamento e desenvolvimento da empresa, mediante os riscos aos quais ela está exposta, podendo assim se resguardar e até elaborar planos estratégicos, com ações necessárias e precisas.

Um sistema de informações é essencial e contribui com eficácia na correta tomada de decisões, pois são estas informações que nortearão o gestor, e conseqüentemente, o levarão à correta administração. 


\section{CONCLUSÕES E RECOMENDAÇÕES}

O fator globalização tem aproximado cada vez mais um País ao outro, da mesma forma que os veículos de comunicações têm mantido o mundo bem informado, também despertam preocupações tempestivas quando determinadas situações ocorrem em qualquer lugar do mundo. E é neste momento que surgem fatos que merecem uma observação mais cautelosa, com maior precisão, pois fatores que provocam prejuízos de natureza econômica em determinados Países, poderão promover prejuízos financeiros para diversos segmentos.

Por este motivo, faz-se necessário que haja uma correta gestão, por meio de estratégias assertivas, que possibilitarão ao gestor evitar prejuízos e minimizar riscos com vistas a alcançar o retorno desejado.

Diante do exposto, o presente artigo destacou a necessidade de que exista um sistema de informações que possa contribuir no momento em que o gestor necessite tomar decisões, tendo à disposição mecanismos que o direcionem e demonstrem qual a real situação financeira da empresa e qual a sua possibilidade de saldar compromissos.

Em se tratando de processo decisório, as demonstrações contábeis apresentam-se como algumas das ferramentas mais utilizadas pelos gestores como fontes de informações, pois refletem em seus relatórios gerenciais os fatos que são extremamente importantes de serem conhecidos para a tomada de decisões. Recomenda-se então, àqueles que desejam dar continuidade ao estudo sobre processos decisórios, a utilização deste trabalho como base de orientação e direcionamento de novas questões, como por exemplo: " por quê as informações são tão importantes para a tomada de decisões?", ou ainda, "as demonstrações contábeis possuem informações relevantes para o gestor, na tomada de decisões?". Uma correta análise administrativa é a base para que o gestor desenvolva estratégias assertivas para a tomada de decisões. 


\section{REFERÊNCIAS}

ASSAF NETO, A. Estrutura e análise de balanços - um enfoque econômico financeiro.São Paulo: Atlas, 1981.

BRADESCO: Demonstrações Contábeis. Disponível em:

http://www.bradescori.com.br/site/conteudo/informacoes-

financeiras/demonstracoes-financeiras.aspx?secaold=721. Acesso em 07 de Novembro de 2010.

CAPELLETTO, Lucio Rodrigues; CORRAR, João Luiz. Índices de risco sistêmico para o setor bancário, 2008. Disponível em: $<$ http://www.eac.fea.usp.br/eac/revista/revista eac.asp?edicao=47>. Acesso em: 28 de Março de 2010.

FREZATTI, Fábio; AGUIAR, Andson Braga de; GUERREIRO, Reinaldo. Diferenciações entre a contabilidade financeira e a contabilidade gerencial : Uma pesquisa empírica a partir de pesquisadores de vários Países, 2007. Disponível em: <www.scielo.br/pdf/rcf/v18n44/a02v1844.pdf>. Acesso em: 28 de Março de 2010.

GITMAN, Lawrence J. Princípios de administração financeira. São Paulo:Pearson Addison Wesley, 2006.

GUERREIRO, Reinaldo. Um modelo de sistema de informação contábil para mensuração do desempenho econômico das atividades empresariais, 1992. Disponível

em: $<$ www.eac.fea.usp.br/cadernos/completos/cad04/modelo sistema.pdf $>$. Acesso em: 28 de Março de 2010.

ITAÚ: Demonstrações Contábeis. Disponível em:

$<$ http://www.itaubba.com.br/portugues/bba/demonstracoes.asp>. Acesso em 07 de Novembro de 2010.

IUDÍCIBUS, Sérgio. Teoria da contabilidade. São Paulo: Atlas, 2007.

SANTOS, Edilene Santana; PONTE, Vera. Modelo de decisão em gestão econômica. $1998 . \quad$ Disponível em: <www.eac.fea.usp.br/cadernos/completos/cad19/modelo.pdf>. Acesso em: 28 de Março de 2010.

SANVICENTE, Antonio Zoratto. A Contabilidade e a teoria da informação. 1990. Disponível

em: <http://www.eac.fea.usp.br/cadernos/completos/cad02/teoria.pdf >. Acesso em: 28 de Março de 2010. 